\title{
Comparison of Personality Structure Models According to the Mutual Correspondence of the Choice of "Identical" People in the Same Life Situations
}

\author{
Andrey Polozov ${ }^{1,}$, , Kristina Polozova ${ }^{1}$, Arthur Akhmetzyanov ${ }^{2}$ \\ ${ }^{1}$ Department of Physical Education, Ural Federal University, Ekaterinburg, Russia \\ ${ }^{2}$ Department of Physical Education, State Pedagogical University, Surgut, Russia \\ Email address: \\ a.a.polozov@mail.ru (A. Polozov), kristina.german.97@inbox.ru (K. Polozova), 79222570710@yandex.ru (A. Akhmetzyanov) \\ ${ }^{*}$ Corresponding author
}

\section{To cite this article:}

Andrey Polozov, Kristina Polozova, Arthur Akhmetzyanov. Comparison of Personality Structure Models According to the Mutual Correspondence of the Choice of "Identical" People in the Same Life Situations. American Journal of Applied Psychology.

Vol. 8, No. 5, 2019, pp. 105-111. doi: 10.11648/j.ajap.20190805.13

Received: September 9, 2019; Accepted: October 12, 2019; Published: October 25, 2019

\begin{abstract}
The purpose of the work is to compare some theories of personality structure according to the mutual correspondence of the choice of "identical" people in the same life situations.. Initially, a test of 47 questions was formed. It opposed each other 11 of the most common motives. The questions of such a test were answered by people assigned to a particular group: by type of personality, by type of character, Big Fife, by type of personality and character. A total of 420 people participated. It was assumed that a better theory would give a higher percentage of mutual correspondence of answers to questions for "identical" people. The largest percentage of the same answers was shown by people close in age with identical types of personality and character. For people over 33, the effect of the age factor on the relevance of responses is significantly reduced. The Big Five concept (TIPI) showed more modest results, apparently explained by the inadequate replacement of only two variants of emotional stability / instability with a more detailed format of 8 character types. The results are unstable due to significant changes in the responses to the motivational test during repeated testing. This suggests that $100 \%$ compliance with any personality model is unattainable due to the difficulties of self-identification of the tested. The results can lead to a change in the methodology for assessing personality structure models, the allocation of alternative abilities from the traditional Big Five to four, and the replacement of emotional stability with character types.
\end{abstract}

Keywords: Personality, Psychotype, Motives, Testing

\section{Introduction}

The history of the personality structure investigation is extremely replete [7]. The main directions in the study of personality psychology are the following:

1. Behavioral psychology (B. Skinner's theory of operant learning)

2. Deep personality psychology (psychoanalysis of Freud, Ego-psychoanalysis of E. Erikson, Transactional analysis of E. Bern)

3. Humanistic psychology of personality (A. Maslow, C. Rogers)

4. Dispositional direction in personality theory (dispositional theory of personality of G. Allport, structural personality trait theory of R. Cattell)

5. Cognitive and socio-cognitive trends in personality psychology (Theory of Personal Constructs of J. Kelly)

6. Psychopathology of personality (Theory of personal accentuations of K. Leonhard, clinical psychology of personality P. S. Gurevich)

7. Existential psychology of personality (American School of Existential Psychology - I. Yalom, R. May, J. Bujengtal, Existential Analysis of A. Langle)

G. Allport considered that out of the 100,000 words given in one of the English dictionaries over 17,000 can characterize the personality properties. "The question of Allport - what is the basic unit of personality? - is still waiting for an answer» [9]. 
Table 1. Five-factor model of personality (B. Goldberg).

\begin{tabular}{lll}
\hline Factor & & Positive pole Negative pole \\
\hline \multirow{2}{*}{ Extraversion } & + & Sociability, assertiveness, high activity \\
& - & Calmness, passivity, restraint \\
Goodwill & + & Kindness, gullibility, warmth \\
& - & Hostility, selfishness, distrust \\
Conscientiousness & + & Organizationality, thoroughness, reliability \\
Emotional & - & Carelessness, negligence, unreliability \\
stability & + & Stability, balance \\
Intelligence & - & Nervousness, irritability \\
& + & Curiosity, creativity \\
\hline
\end{tabular}

direct predecessor of the Big Five appeared to be a 3-factor personality model of G. Eysenck (extraversion, neuroticism and psychoticism). Norman (1963) first named the five factors of extroversion, goodwill, conscientiousness, emotional stability and culture. The term itself was in the Goldberg's work (1981).

The Big Five got the NEO-PI-R question [18], the shortened version of the test consisting of 60 questions. The most well-known short questionnaire on the diagnosis of the Big Five consists of 10 questions of the personality surveys (TIPI) of Gosling, Rentfrey and Swann [19].

The Big Five is a dispositional personality model. The

Table 2. NEO-PI-R test indicators (Costa \& McCrae, 1992) and MBTI, TX (character types).

\begin{tabular}{|c|c|c|}
\hline Factor & & MBTI, TX \\
\hline Self control Impulsiveness & $\begin{array}{l}\text { accuracy, perseverance, responsibility, self-control behavior, forethought } \\
\text { carelessness, lack of perseverance, irresponsibility, impulsiveness, nonchalance }\end{array}$ & $\begin{array}{l}\text { Rationality } \\
\text { Irrationality }\end{array}$ \\
\hline Extraversion Introversion & $\begin{array}{l}\text { activity, domination, sociability, search for impressions, manifestation of guilt feelings } \\
\text { passivity, subordination, isolation, avoidance of impressions, avoidance of guilt feelings }\end{array}$ & $\begin{array}{l}\text { Extraversion } \\
\text { Introversion }\end{array}$ \\
\hline Expressiveness Practicality & $\begin{array}{l}\text { curiosity, artistry, sensitivity, plasticity } \\
\text { conservatism, realism, lack of artistry, insensitivity, rigidity }\end{array}$ & $\begin{array}{l}\text { Intuitiveness } \\
\text { Sensory }\end{array}$ \\
\hline Attachment Isolation & $\begin{array}{l}\text { warmth, cooperation, gullibility, understanding, respect of others } \\
\text { indifference, rivalry, suspicion, misunderstanding, self-esteem }\end{array}$ & $\begin{array}{l}\text { Ethics } \\
\text { Logics }\end{array}$ \\
\hline $\begin{array}{l}\text { Emotional stability } \\
\text { Emotional Instability }\end{array}$ & $\begin{array}{l}\text { carelessness, relaxation, emotional comfort, self-sufficiency, emotional stability } \\
\text { anxiety, tension, depression, self-criticism, emotional lability }\end{array}$ & Types of character \\
\hline
\end{tabular}

The correlations between Costa \& McCrae factors although is statistically significant but remain very moderate, on average $r=0.26$, and do not exceed $r=0.35$ on individual scales (John \& Soto, 2007; John et al., 2008 on a sample of 829 students at Berkeley). As can be seen from the above tables, discrepancies between researchers have more conceptual and terminological nature. At the same time, all questions of the intellectual, cognitive sphere remain outside the model.

The personality structure of persons within clinical populations may not be fundamentally different from the personality structure of persons who have not sought treatment for their maladaptive personality traits [16]. Indeed, there has long been an interest in understanding personality disorders as maladaptive variants of general personality structure. Presented herein is an understanding of personality disorder from the perspective of basic personality research; more specifically, the five factor model (FFM) of general personality structure. Potential advantages of understanding personality disorders from the perspective of the FFM are provided.

The authors [11] believe that the five personal qualities can really work to choose a profession. "The ratio of personality size of the Big Five (extraversion, emotional stability, consent, conscientiousness and openness to experience) to the three performance criteria (qualifications of work, training and personnel data) for five professional groups (professionals, police, managers, sales and qualified/semiskilled specialists) was investigated. The results showed that one of personality factor determined, conscientiousness, has a consistent relationship with all performance criteria for all professional groups." However, the final conclusions are blurred, uncertain. Doctrine can be useful in determining the profession, but how much? How can I find out what kind of profession suits this person?

The authors [12] attempted to expand the range of personality indicators. "We are considering the relationship between the Big Five personality and the four-factor model of cultural intelligence (CQ) - metacognitive CQ, cognitive CQ, motivational CQ and behavioral CQ." However, an acceptable solution is not given.

The authors [13] noted the following: "correlation analyzes showed that four MBTI indices measured aspects of four out of the five main normal personality factors." The five personal qualities became the crystallization center of works on the personality psychology. Each new work tries to find any correlation of these 5 qualities with the authors used. A positive response is perceived with relief as a right to a continued its existence.

"This meta-analysis used 9 literature search strategies to examine 137 distinct personality constructs as correlates of subjective well-being (SWB). Personality was found to be equally predictive of life satisfaction, happiness, and positive affect, but significantly less predictive of negative affect. The traits most closely associated with SWB were repressivedefensiveness, trust, emotional stability, locus of controlchance, desire for control, hardiness, positive affectivity, private collective self-esteem, and tension". [14]

Character types are still considered a disease. [4]

The authors of all papers try to expand the field of indicators used. However, all these works do not answer the main question - how full do these five personal qualities characterize the person? Writing another work where there is a correlation of different indicators among themselves seems a hopeless task. It seems more appropriate to find people who are identical in their characteristics and compare their 
answers to the same questions. However, it is difficult to do this for the above-mentioned five personal qualities. We can easily relate a person to extroverts or introverts. But there is no specific indicator in the intellect or neuroticism. This is a separate numerical scale where all people tested can be located at once. Thus, the concept of the five personal qualities becomes unverifiable by comparing the answers of identical people, since it is not possible to single out the latter from the general group. You can either believe or not believe in this concept.

Personality structure in the works of other authors:

Z. Freud (1899) Conscious (ego), unconscious (moral norms, instincts of life and death)

S. L. Rubinstein (1946): direction, ability, temperament and character

R. Kettel (1950): interests, abilities, temperament

A. G. Kovalev (1963): ability, direction, character

K. K. Platonov (1965): socially conditioned inclinations, experience, biologically determined inclinations, individual characteristics

V. N. Myasishchev (1969): direction, level of development, temperament, personality structure

V. A. Gansen (1984): temperament, direction, character and ability.

K. Leonhard (1987): the focus of interests, will and feelings, associative and intellectual

V. S. Merlin (1959) direction, character, ability (monograph "Essay on the individual psychology").

S. S. Bubnova (1999) - values-ideals, values-personal qualities and value ways of behavior

M. Buckingham and K. Kofman (2005) talents of achievement, intellection, interaction.

N. I. Kozlov (2012), direction, perception of the world, experience, ability, temperament and character, body image.

Most researchers are close to a consensus on the personality structure consisting of three areas: the focus of interests, intelligence and character. Different authors add factors that may be secondary and correlated with them.

In 2005 [2] it was also suggested that spheres we can place the types known to all in each of the three:

1. 16 personality types (PT) of Myers-Briggs (Jung K. G. etc): ENTP, ISFP, etc., into the "focus of interests";

2. 8 known character types (CT) (Kretschmer E., Leonhard K., Lowen A., Lichko A. E., Merton R., Horney K., Shostrom E.) into the sphere of "will and feelings";

3. 7 intellect types of Howard Gardner ("Boundaries of Reason", 1983): analytical, linguistic, spatial, musical, bodily-kinesthetic, interpersonal and intrapersonal intelligence (TI) into the "associative intellectual".

"Intellect is traditionally considered an area of individual differences which is completely separated from the personality." (P. Corr, 2009). For a long time, the concept of intelligence was largely identified with IQ. Its average value grew by 3-7 points over a decade. A study by R. Lynn and E. Dutton showed that the average IQ of the French fell by 4 points between 1999 and 2009. This revived the debate over whether the intellect is innate or acquired. The level of spelling literacy of the population has decreased because of general computerization. Intelligence is always reduced if it is not used.

The contours of 8 character types are gradually emerging from work varieties in the sphere of "will and feelings". McWilliams (1998), Naranjo (1998), Popov, View (2000), Lowen (2000), Horney (1995) pointed out:

1. Schizoid - loneliness, fantasy, coldness, selectivity

2. Narcissus-envy, overestimation of oneself, need for devotion

3. Paranoid-suspiciousness, neglect of others, intolerance

4. Compulsive-doubt, pedantry, scrupulousness interfering business.

5. Psychopathic-heartlessness, the desire "to be the most", neglect

6. Hysterical-demonstrativeness, theatricality, attracting attention

7. Depressive-conciliation, fear of being abandoned, depression

8. Masochistic-patience in the hope of the subsequent good.

Such a transformation completely corresponds to the works of S. L. Rubinshtein, R. Kettle, K. K. Platonov, A. G. Kovalev, V. N. Myasishchev, Hansen, V.S. Merlin, K. Leonhard, M. Buckingham, K. Kofman. However, some authors try to add several factors. It is easy to explain the meaningless inclusion of temperament in this list. If we write the abbreviation EP "extravert" and "decisive", then this combination can be perceived as known to all choleric persons. EJ is a sanguine person; NJ is a phlegmatic one; NP is a melancholic one. In addition, people with hysterical CT are also perceived as choleric and masochistic CT do as melancholic one. Thus, the existence of temperaments can be explained within a more detailed personality structure where 128 positions $\mathrm{PT}+\mathrm{CT}$ are represented instead of 4 positions of temperament.

The object of the work is to compare some theories of the personality structure by the mutual precision of the choice of people with an identical typological structure in the same life situations.

To solve this problem it is necessary to test people reliably and to choose from them "identical" from the point of view of this or that doctrine. Then these "identical" people are given tests which provide an opportunity to choose in situations that have been or will occur in their lives.

Tasks of the study:

1. choose 11 most important motives in everyday life,

2. select groups of people with the same typological characteristics,

3. compare the precision between the motivational test answers of such people.

\section{Method}

Sorting of participants. There are more than 420 participants. They were tested for PT (MBTI) and CT [2]. 
Re-testing was conducted in a month. If the results of the answers to the tests did not coincide, the participant was excluded from further work.

\subsection{Method for the Motive Significance Estimation}

We used a rating system that was well applied in sports [15]. The use of the rating system allows minimizing the number of questions and, in this context, to expand the range of motives studied. If you take 10 motives and want to arrange them relative to each other, then comparing the answers to 10 questions in pairs, you must ask 550 questions. No one will face it out. People begin to answer in random or completely give up. The rating allows you to get out of the situation leaving 11 motives and 47 cases. Let us give a practical example of a system of linear equations.

Table 3. Example of a linear equation system.

\begin{tabular}{llllll}
\hline Motive & $\mathbf{1}$ & $\mathbf{2}$ & $\mathbf{3}$ & & Rt \\
\hline A. Material & & $6: 4$ & $7: 3$ & $13: 7$ & 2200 \\
B. Power & $4: 6$ & & $6: 4$ & $10: 10$ & 2000 \\
C. Achievement & $3: 7$ & $4: 6$ & & $7: 13$ & 1800 \\
\hline
\end{tabular}

$$
\left\{\begin{array}{c}
\operatorname{Rt}(A)=\left(\frac{6+4}{13+7}\right) \times \operatorname{Rt}(B)+\left(\frac{7+3}{13+7}\right) \times \operatorname{Rt}(C)+\frac{13-7}{13+7} \times 1000 \\
\operatorname{Rt}(B)=\left(\frac{6+4}{10+10}\right) \times \operatorname{Rt}(A)+\left(\frac{4-6}{10+10}\right) \times \operatorname{Rt}(C)+\frac{10-10}{10+10} \times 1000 \\
\operatorname{Rt}(C)=\left(\frac{7+3}{7+13}\right) \times \operatorname{Rt}(A)+\left(\frac{6+4}{7+13}\right) \times \operatorname{Rt}(B)+\frac{7-13}{7+13} \times 1000 \\
(\operatorname{Rt}(A)+\operatorname{Rt}(B)+\operatorname{Rt}(C)) / 3=2000
\end{array}\right.
$$

Having already obtained the Rt values for 1 and 2 motivations for the given person $i$, one can estimate the probability of his choice of $\mathrm{p}$ for a pairwise comparison:

$$
\mathrm{p}=(1000+(\operatorname{Rti}(1)-\operatorname{Rti}(2))) / 2000
$$

The answers of people with the same PT, CT, PT + CT, etc. were compared. The average value for a pairwise comparison of the answers of all persons tested was estimated.

\subsection{The Method of the Motivational Sphere Research}

The full test consists of 47 questions [15]. A number of frequently occurring life situations were taken. There is an approximately equivalent choice of alternatives to behaviors in those situations.

Example. The woman decides - to give birth to one more, a second child, or not. It is obviously this difficult choice happens in the life of every woman and any choice will not be easy. On the one hand, she would like to have more children. And this is natural. However, on the other hand this means worsening the condition of other part of the family. We interpret the situation as a humanistic motive against the motive of the material.

The first stage of the test was to filter out questions with unequal answers. It took us about a year to displace such questions by others, more "neutral".
At the next stage, the adequacy of the perception of the questions was checked. In particular, the participants were asked which of the 11 motives they would include each of the alternatives mentioned in the question. Ambiguously perceived questions were replaced by others.

A separate study included the stability in the answers while retesting, the most inadequate questions being replaced. The questions were stable if both answers were emotionally significant for the participant. There were other aspects of testing (Skorykh S., 2012).

We took the following motives for our research.

1. Cognition - the desire to learn new patterns, the motivation for activity by the process and content of activity rather than by external factors.

2. Negative - motivations caused by the realization of some troubles, inconveniences that may arise in case of nonperformance.

3. Communication - this is a communication that brings satisfaction, it's breathtaking, people like it.

4. Material - the motive of material gain

5. Success - an achievement highly valued by society. The motive is connected with self-esteem, ambition, vanity.

6. Power - governance, domination at the level of society. It is the desire of the subject to influence people, to determine and regulate their activities.

7. Humanistic - the ability to reckon with the interests of others, the motive of duty and responsibility to society, a group, individuals.

8. Self-realization - according to A. Maslow, this is the desire to fully realize their abilities and the desire to feel their competence.

9. Aesthetic - the desire for harmony, aesthetic perfection.

10. Independence - freedom in decision-making.

11. Achievements - the desire to achieve high results and skill in the activity; it manifests itself in the desire to fulfill complex tasks.

So, we have 47 such questions. If you fill out the answers arbitrarily, you get about $50 \%$.

\subsection{Comparison Criteria}

In the scientific literature, the correlation coefficient is generally accepted. In this case, we need to find a more specific criterion that would fully reflect the whole picture and at the same time be proportional to the correlation coefficient. The author considers such criterion as the average percentage value of answers coincidence to questions from a motivational test of people who are identical from the point of view of a particular theory. Covering all the doctrines is problematic. Therefore, noncompetitive theories are abandoned in advance (temperament, etc.). Thus, the Myers-Briggs typology, character types, and the big five personality traits as an opponent of the TL + TX + TI concept are chosen. The answers of people with the same TL, TX and with the same $\mathrm{TL}+\mathrm{TX}$, etc. are compared. The mean value was estimated when pairwise matching the responses of all subjects. 


\section{Results}

The main experiment was preceded by a large number of preliminary experiments.

The sustainability factor of the motivational sphere. A study of the motivational sphere of students of the Ural Federal University named after the first president B. N. Yeltsin for six months were conducted. 420 students and 80 employees took part in the research. The expected calculated value of the level of each motive was calculated from the obtained tables and it was compared with the participant answers (Skorykh SA, 2012). The obtained deviations leveled out and a table of such deviations was formed. Now to obtain the calculated value of the motive it is necessary not only to obtain the PT and CT value, but also the average value of the deviation of this motive for a given age from the tables obtained for 16 to 50 years old (Polozov A. A., 2012). So a model for behavior prediction for each module according to the given psychological structure taking into account age was formed.

An analysis of the motivational coach estimation impact on the motivational priorities of the students was made. The groups of coaches in track and field athletics of the national team of Sverdlovsk region were analyzed. Students working with these trainers for at least 5 years and having a grade not lower than MS were tested in these groups. There were 30 pairs student-coach after PT and CT testing. Then a preliminary prediction for motivational priorities based on the tables obtained was made. Then the prediction was compared with the actual data.

Table 4. Comparative analysis of the estimation impact of the coach motivation priorities on the motivational assessment of the students of group No 1.

\begin{tabular}{|c|c|c|c|c|c|c|c|}
\hline \multicolumn{8}{|c|}{ Impact of the coach motivation priorities on the motivational assessment of the students } \\
\hline & In fact & Calculation & In fact & Calculation & In fact & Calculation & In fact \\
\hline \multirow[t]{2}{*}{ Motives } & Coach & K. U. 24 & K. U. 24 & Ch. I. 45 & Ch. I. 45 & O. A. 24 & O. A. 24 \\
\hline & INTJ Schizoid & INFP Hysterical & INFP Hysterical & ISTP Schizoid & ISTP Schizoid & ISFJ Hysterical & ISFJ Hysterical \\
\hline Cognition & 1796 & 2484 & 2219 & 2404 & 2027 & 2291 & 1770 \\
\hline Negative & 2000 & 2246 & 2404 & 2237 & 2016 & 1935 & 2070 \\
\hline Communication & 1955 & 2055 & 2665 & 2335 & 1929 & 2165 & 2389 \\
\hline Material & 2681 & 2251 & 2296 & 2254 & 2478 & 2126 & 2481 \\
\hline Success & 2720 & 1544 & 2280 & 2233 & 2518 & 1765 & 2113 \\
\hline Power & 2087 & 2312 & 1692 & 2228 & 2350 & 2577 & 2010 \\
\hline Humanistic & 2516 & 2155 & 2525 & 2013 & 2494 & 2108 & 2687 \\
\hline Self-realization & 2391 & 2691 & 2239 & 2203 & 2417 & 2932 & 2388 \\
\hline Aesthetic & 2001 & 1891 & 1749 & 2024 & 1973 & 1679 & 2227 \\
\hline Independence & 2035 & 2349 & 2477 & 2151 & 1980 & 2157 & 2047 \\
\hline Achievements & 2018 & 2325 & 1655 & 2118 & 2018 & 2567 & 2018 \\
\hline Correlation coefficient & & -0.334 & 0.212 & -0.220 & 0.899 & -0.106 & 0.606 \\
\hline
\end{tabular}

The correlation coefficient increased with the transition from the expected result to the actually obtained one in all 30 coach-student pairs. This means that the coach in the process of his work actualizes the most significant motives for his students. Motivational sphere of the student likewise are influenced by parents, school friends, etc. This means that we cannot know the real motives of the youngest athlete. We will deal with the induced, transformed by the surrounding motivation. This is a factor that does not allow us to expect $100 \%$ compliance with people who are identical in terms of different concepts.

The sustainability factor of the motivational sphere of age. Can we compare the test results of people of different ages? This forced us to another experiment - the observation of changes in the motivation of people with the same combination of PT + CT. We chose "Schizoid" CT and PT of ISTJ of different ages for two reasons: there are a lot of such people in the sport sphere and people with such PT are especially reliable in their answers to the test questions. Half of the people were traditionally eliminated after repeated testing in a month. The correlation procedure with the results was performed.

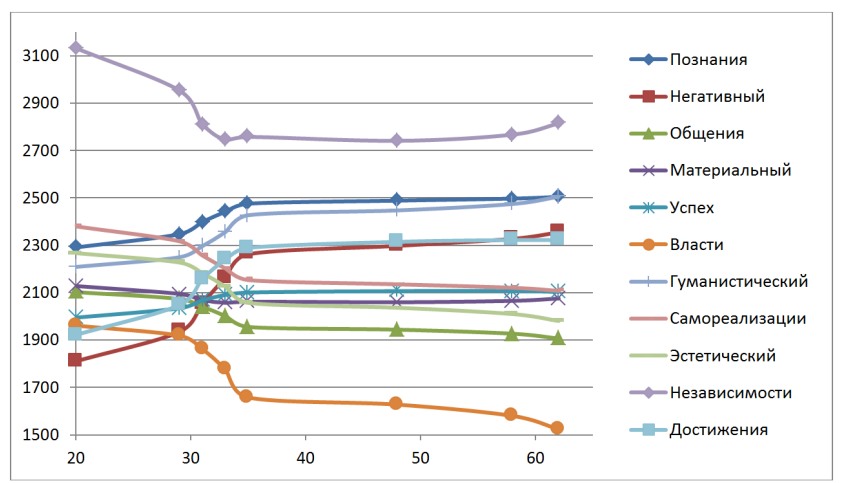

Figure 1. Evolution of the motive priority for Schizoid'CT, ISTJ TL from age.

Something similar was got in other combinations of $\mathrm{PT}+\mathrm{CT}$, but there are fewer plot points. You can see that the motivation of people of different ages with the same combination of $\mathrm{PT}+\mathrm{CT}$ essentially changes up to 33 years old. During this period we are influenced by parents, friends, school or university. At this time our motivation is largely induced by the immediate environment (parents, coach). At the age of more than 32 years old study and transition to an economic competitive environment are completed and a family is created. During this period motivation is much 
more sustainable. This allows you to see the desired identity of answers. However, it is preferable to compare the responses of people closest in age.

Factor of answers adequacy. If the question is asked unexpectedly, then you may not get a weighted answer. Any test question is further rethought by the subjects according to their life, situational experience, etc. We managed to repeat the motivational test for 30 students. The results obtained corresponded to each other by $89 \%$, which should be considered the ultimate result value. This result should be attributed to the intellectual abilities of a person in terms of adequate self-identification.

So, we cannot count on $100 \%$ compliance of the final results of the comparison of answers in the motivational test of people with an identical personality structure. The factor of answers adequacy reduces this number to $89 \%$. Further, this indicator will be reduced by the factors of variability of the motivational sphere from age and, in particular, the factor of sustainability of the motivational sphere, and many others.

A small number of questions give a big error. For example, if the participant will receive a balance of $3: 3$ or $4: 2$ from 6 situations of choosing one motive in comparison with others, then this will give a deviation of 330 rating points.

We did not use TI. For example, intellectually gifted people have a much higher status of the motive of cognition. However, it was extremely difficult to find identical people by $\mathrm{PT}+\mathrm{CT}+\mathrm{TI}$.

Thus, we are entitled to expect results at the level of 65 $70 \%$ as high as possible and to be satisfied with this level of results. The traditional form of presenting results in the format of the correlation coefficient does not give us the possibility of such a presentation of data.

The main experiment. To continue the experiment we created a website www.profurfu.ru. Applicants were tested. The specificity of this format of the experiment was that retesting of dichotomies, types of character were included in the test itself (at the beginning and at the end). Here are the data only those who equally answered the first and second test. Those were not more than $50 \%$. Over the three years of operation of the site, we were able to get over 400 authentic tests.

The tests of intelligence were of the greatest difficulty. The decision to make three tests from the well-known IQ test linguistic, analytical and spatial - was the most debatable. A well-known test for abstract logic and concentration of attention were also used. The sport test compared the participant results of the test with the standards of the GTO. The musical test assumed the presence of musical competence. The interpersonal test was also developed by us on the basis of a comparison of the well-known personality description to the description of their $\mathrm{PT}+\mathrm{CT}$. Intrapersonal intelligence was estimated by the percentage of the choice in pairs in extraversion-introversion and other final choices. There were 9 tests of intelligence. The data of these tests were compared with the average value of all participants. The leader in this priority was TI1, the second - TI2 and so on. Participants with the difference in age of 3 years (Age 3), 7 years (Age 7), one gender ( $\mathrm{Pol})$, with identical dominant motive (Motiv) were also compared.

Table 5. Comparison of site data www.profurfu.ru for 2 years of work.

\begin{tabular}{|c|c|c|}
\hline Compare testers & Conformity & The number of compared pairs \\
\hline $\mathrm{TL}+\mathrm{TX}+\mathrm{TI} 2$ & 0.557 & 5 \\
\hline $\mathrm{TL}$ & 0.581 & 601 \\
\hline TX & 0.594 & 1364 \\
\hline $\mathrm{TL}+\mathrm{TX}+\mathrm{TI}+\mathrm{Pol}+\mathrm{Age} 7$ & 0.596 & 6 \\
\hline $\mathrm{TL}+\mathrm{TX}+\mathrm{Pol}+\mathrm{TI} 1+$ Age $7+$ Motiv & 0.596 & 6 \\
\hline $\mathrm{TL}+\mathrm{TX}+\mathrm{TI}+\mathrm{Age} 3$ & 0.602 & 29 \\
\hline TL+TX+Motiv+Pol+TI1+Age 3 & 0.604 & 5 \\
\hline Big Five (TIPI) & 0.605 & 29 \\
\hline ТЛ+ТХ+Age 3 & 0.607 & 33 \\
\hline $\mathrm{TL}+\mathrm{TX}+\mathrm{TI}+\mathrm{Pol}$ & 0.609 & 10 \\
\hline TL+TX+Motiv+Pol+TI1 & 0.609 & 10 \\
\hline ТЛ+ТХ+Age 3+Pol & 0.610 & 21 \\
\hline TL+TX+TI+Age 7 & 0.611 & 47 \\
\hline ТЛ+ТХ+Age 7+Pol & 0.612 & 31 \\
\hline ТЛ+ТХ+Age 7 & 0.614 & 55 \\
\hline $\mathrm{TL}+\mathrm{TX}$ & 0.615 & 105 \\
\hline $\mathrm{TL}+\mathrm{TX}+$ Motiv & 0.615 & 105 \\
\hline $\mathrm{TL}+\mathrm{TX}+\mathrm{TI} 12$ & 0.617 & 17 \\
\hline ТЛ+ТХ+Pol & 0.622 & 55 \\
\hline $\mathrm{TL}+\mathrm{TX}+$ Motiv $+\mathrm{Pol}$ & 0.622 & 55 \\
\hline $\mathrm{TL}+\mathrm{TX}+\mathrm{TI} 1$ & 0.629 & 22 \\
\hline TL+TX+TI1+Тіјвнутл>0 & 0.638 & 5 \\
\hline TL+TX+TI1+Тіјвнутл>30\% & 0.644 & 4 \\
\hline TL+TX+TI1+Тіјвнутл>40\% & 0.649 & 2 \\
\hline
\end{tabular}

You can see the concept of PT+CT+TI to have the advantage of a percentage of identical answers for 47 questions (among 22 compared pairs). 


\section{Conclusions}

Most psychologists who study the personality structure are close to consensus - the person consists of 3 spheres: the orientation of interests, character and intellectual abilities. The other directions, such as temperament, for instance, can simply be a variation analogue from the chosen spheres. In 2005 the author suggested that in each of the three spheres we can place the well-known types: 16 personality types (PT) of Myers-Briggs, Jung K. G. - in the "focus of interests"; 8 known types of character (CT) - in the sphere of "will and feelings"; 7 types of intelligence (TI) - in "associativeintellectual". This version of the personality structure was designated $\mathrm{PT}+\mathrm{CT}+\mathrm{TI}$. Any doctrine in psychology must prove its consistency with the convergence of expected and actual behavior. To do this it is necessary to take the most common life situations of the choice between two alternatives and to estimate the percentage of convergence in the pairwise comparison in the answers given by people from the group homogeneous for the given doctrine. Comparing the answers of people with the same PT or CT we obtained the answer precision of 58-59\%. People who are identical in PT, CT and the most developed TI - PT+CT+TI1 - 63\%. This percentage increases with increasing capacity for selfidentification. Close to age representatives of ISTJ with schizoid CT showed $67 \%$. We could not get $100 \%$ of the result because of the limited ability of participant selfidentification and induced by the surrounding motivation. To verify in a similar way the known concept of the five leading personal qualities is not possible because of the numerical uncertainty of these qualities.

\section{References}

[1] Leonhard K. Accentuated personalities./Transl. from German/Preface. and ed. V. M. Bleicher. $-2^{\text {nd }}$ ed. sr. - K.: High school. Head Publishing House, 1989. - 375 p.

[2] Polozov A. A. Psychological portraits of the sports club staff// Sports psychologist, №3 (6), 2005.

[3] Modules of the psychological structure in sports./A. A. Polozov, N. N. Polozova / M.: Publishing house "Soviet Sport", 2009.

[4] Talanov V. L., Malkina-Pykh I. G. Handbook of practical psychologist/St. Petersburg: Owl, M.: EKSMO, 2002-928 p.
[5] Freud S. Psychology of the unconscious.-M., 1989.

[6] Hekhausen X. Motivation and activity. V. 1-2.-M.-1986.

[7] Hjell L., Singler D. Theories of personality. $3^{\text {rd }}$ ed.-St. Petersburg. 607 p.

[8] A. V. Petrovsky, Personality in Psychology from the Perspective of the Systems Approach/Questions of Psychology, 1981.

[9] The Cambridge Handbook of Personality Psychology/Edited by Philip J. Corr and Gerald Matthews/ Cambridge University Press. 2009. c. 849.

[10] Polozov A. A., Shurmanov Ye. G. "Create your team in sports, in life, in business." M.: Soviet sports. 2013.-434 p. p.: Figure.

[11] The big five personality dimensions and job performance: a meta-analysis/M Barrick, M Mount/Personnel psychology vol. 44, issue 1, march 1991, pages 1-26

[12] Personality Correlates of the Four-Factor Model of Cultural Intelligence/Soon Ang, Linn Van Dyne, Christine Koh/ Group \& Organization Management. 2006, vol. 31.

[13] Reinterpreting the Myers-Briggs Type Indicator From the Perspective of the Five-Factor Model of Personality/Robert R. McCrae, Paul T. Costa Jr./Journal of personality Volume 57, Issue1 March 1989 Pages 17-40.

[14] The happy personality: A meta-analysis of 137 personality traits and subjective well-being. /DeNeve, K. M., Cooper, H./Psychological Bulletin, 1998, 124 (2), 197-229.

[15] Polozov A., Brekhova L. Methods of Testing a Large Number of Motives for Vocational Guidance. Education Journal. Vol. 8, No. 5, 2019, pp. 175-184. doi: 10.11648/j.edu.20190805.12.

[16] Widiger T., Crego C. Basic personality model/Current Opinion in Psychology. Volume 21, June 2018, Pages 18-22 June 2018, Pages 18-22.

[17] Aslinger, E. N., Manuck, S. B., Pilkonis, P. A., Simms, L. J., \& Wright, A. G. C. (2018). Narcissist or narcissistic? Evaluation of the latent structure of narcissistic personality disorder. Journal of Abnormal Psychology, 127 (5), 496-502.

[18] Costa, Paul T., McCrae, Robert R. Normal personality assessment in clinical practice: The NEO Personality Inventory./Psychological Assessment, Vol 4 (1), Mar 1992, 513.

[19] S. Gosling, P. Rentfrow, W. SwannJr. Very brief measure of the Big-Five personality domains/Journal of Research in Personality Volume 37, Issue 6, December 2003, Pages 504528 December 2003, Pages 504-528. 